\title{
Scientific Breakthrough Based on Natural Creation: "1 Diamond with 7 Eyes
}

\author{
Hendry Izaac Elim ${ }^{1,2,3,4,5 *}$ \\ ${ }^{1}$ Department of Physics, Nanomaterials for Photonics Nanotechnology Laboratory (N4PN Lab.), Pattimura University (UNPATTI), Indonesia \\ ${ }^{2}$ Nanotechnology Research Center and Innovative Creation (PPNRI-LEMLIT), Research Center of Pattimura University, Indonesia \\ ${ }^{3}$ Multidisciplinary Research Center of Excellence (MrCE), UNPATTI, Indonesia \\ ${ }^{4}$ Department Biology, Multidisciplinary Bioinformatics Laboratory (MB Lab.), Indonesia \\ ${ }^{5}$ Department of Physics, Theoretical Physics Laboratory (TP Lab.), UNPATTI, Indonesia
}

*Corresponding author: Hendry Izaac Elim, Department of Physics, Pattimura University, Ambon, Indonesia

Submission: 㘹 May 18, 2018; Published: 筒 May 22, 2018

\begin{abstract}
The different between a breakthrough scientist and a normal scientist is mainly on their natural creation. A breakthrough scientist was born to be an extraordinary man chosen before born, and blessed during growing in the womb [1]. This is called as the beginning of natural creation of human integrity [2] to be an excellent scientist in the future. While a normal scientist was created in GOD (YaHWeH) own image and picture with the fair abilities in identifying both knowledge of good and evil [1]. Here, one explores a significant explanation on how a scientific breakthrough was based on a natural creation like a diamond with seven eyes [1]. Such seven eyes can be divided as follows [1]:

I. Brain and logic;

II. Heart and soul;

III. Desires and sex;

IV. Spirit and work;

V. Collaboration and contribution;

VI. Cooperation and risk management; and

VII. Novel (new) outputs.

These deep understanding [3,4] were then applied into nanomedicine and nanotechnology breakthrough research, for instance in finding an incredible herbal medicine called as Love herbal (LH) medicine [5-10]. We obtained that each eye has its own unique ability and function. Furthermore, they link one another in a multitasking healing system. Point by point description is shortly presented. This review letter of research can be applicable and suitable for various different fields of innovative investigations in scientific report and nature.
\end{abstract}

\begin{abstract}
A Letter
The nature of creation is still a mystery in an ongoing frontier research even the advancement of human technology in this 21st century has been exponentially improved in various ways, multidisciplinary fields, and science breakthroughs [11]. Some remarkable scientists did marvelous efforts to discover something novel, for example the invention of HIV virus [12-15], and then realized that they were not the first one even they already made it famous in society through their prominent scientific contributions. In fact, the former scientist from France, Francoise Barre-Sinoussi got the Nobel winner 26 years later by discovering it in her laboratory 2 years before it was widely well known in 1984.
\end{abstract}

In this compact review and research, we provide a significant different between a breakthrough scientist and a normal scientist especially on their natural creation abilities associated with their works. At least $\sim 1500$ years before Jesus Christ, Moses, a scientific prophet already did various complex investigation about the last 80 years of his mobile life on earth until the end of his 120 years old experienced life written in Holy Bible, and it was supported incredibly by many different prophets living in different interval of hundreds years such as Jeremiah, David, Zechariah, and Apostle John [1]. According to such integrable understanding, a breakthrough scientist was born to be an extraordinary man, a messenger chosen before born, and blessed during growing in the womb [1]. 
Such undeniable origin of natural creation of human integrity [2] was an excellent promising future scientist. On the other hand, a normal scientist was created by LORD (Jehovah/ההה) as well in His own image and picture with the fair abilities in identifying both knowledge of good and evil [1]. The main sustainability of man was initially pure like a diamond with seven eyes [1]. Such seven eyes stand for [1]
i. Brain and logic
ii. Heart and soul
iii. Desires and sex
iv. $\quad$ Spirit and work

v. Collaboration and contribution

vi. Cooperation and risk management and

vii. New outputs

By implementing this kind of " 1 diamond with 7 eyes" for instance in a multitasking research on nanomedicine and nanotechnology breakthrough research, we obtained a prominent herbal medicine fabricated from natural creation of zingiberaceae fruits (Halmahera/ Maluku Golobe) [5-10] named as Love herbal (LH) medicine exhibited amazing 7 anti-deceases in 1 LH medicine as depicted in Figure 1 The seven different types of multitasking healing in a LH medicine are consisting of

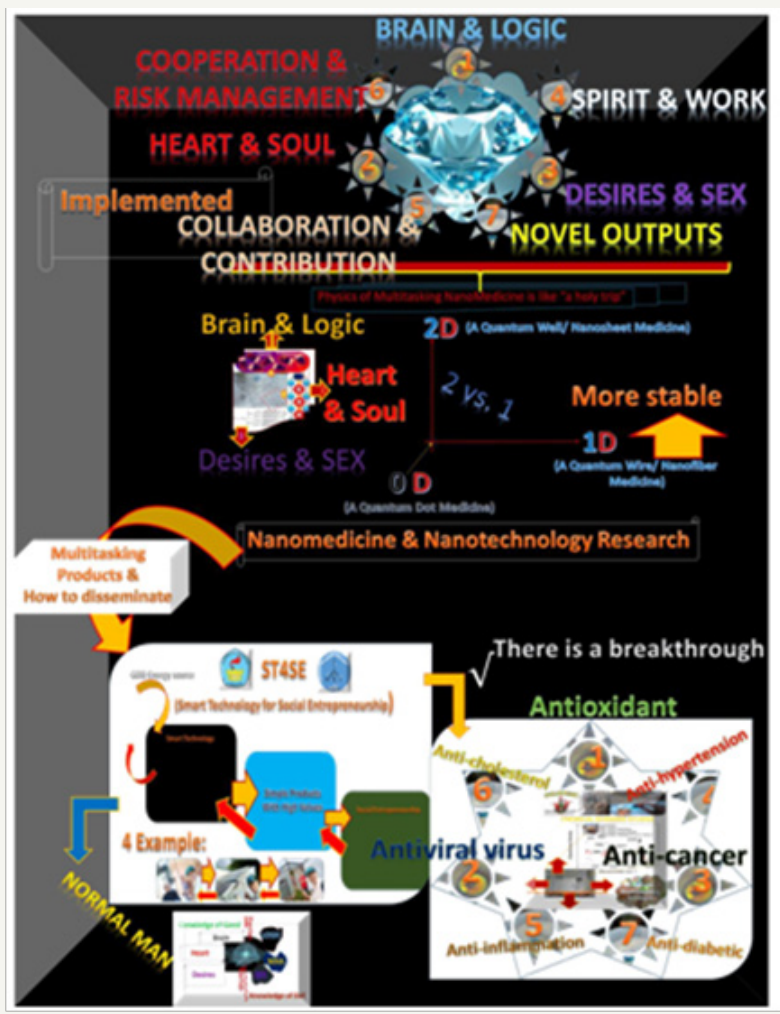

Figure 1: Multitasking implementation on how to carry out a scientific breakthrough based on natural creation is like a "1 Diamond with 7 Eyes" that makes a multitasking contributed impacts in various society.

i. Ultralarge antioxidant of $6.54 \mathrm{ng} / \mathrm{mL}$ [16], one of the largest non-enzymatic antioxidant on earth with its content of flavonoid [7];

ii. Prominent Anti retrovirus (RTU) such as HIV [5,6,8] and Hepatitis;

iii. Fair chemotherapy herbal drug or an anti-cancer medicine [10];

iv. Anti-hypertension due to $5.88 \%$ content of 2,6 Diethyl Pyridine [17];

v. Anti-inflammation due to its large $12.46 \%$ content of $\alpha$-humulene or $\alpha$-caryophyllene [17]; vi. Anti-cholesterol due to $6.08 \%$ of Cholest-5-en-3-one, 4,4-dimethyl [17]; and

vii. Anti-diabetic because of its 3.8\% of Stigmast-5-en-3-ol, 3 beta [17].

Such significant findings are very different from the normal regulation supplements and drugs produced in USA by their Foods and Drugs Association (FDA) in which many costumers and pharmacy companies got more benefits by producing 1 excellent drug to 1 target. That is the core point of the different between breakthrough scientist and their products with those of normal scientist. Furthermore, about $\sim 600$ years before Jesus Christ, a prominent prophet Daniel, and a simple prophet Ezekiel living at the same interval time in two big earthly kingdoms of Babylonian 
and Persia wrote how LORD inspired them to understand on how to make supplements from fruits, and medicine from leafs recorded in the books of Daniel chapter 4 verse 12, and Ezekiel of chapter 47 in verse 12 , respectively. Therefore, I would say that a breakthrough scientist is actually a heavenly scientist, and a normal scientist is an earthly scientist. The earthly scientist used many different equipment invented by heavenly scientists. Moreover we obtained that "each eye of the diamond" has its own unique ability and function. In addition, they connected integratedly as one multitasking healing system.

\section{Conclusion}

This review letter of research can be applicable and suitable for various different fields particularly in expanding innovative possibility in frontier multitasking investigations including in understanding scientific data, and the origin of nature.

\section{Acknowledgement}

Hendry Izaac Elim is generously grateful to thank to Prof. Dr. M.J. Saptenno, one of the breakthrough president of Pattimura university since it was built on $23^{\text {rd }}$ April 1963 who supported us by encouraging and providing research grant of Riset Unggulan Daerah No. 741/UN13/SK/2017 about energy research funded by Pattimura university, Ambon, Indonesia.

\section{References}

1. Holy Bible, for example in Jeremiah 1:5; Genesis 1:26-27; Zechariah 3:9; Revelation 1:4;4:5; 21:5; Isaiah 9:6; 11:2.

2. Elim HI (2015) Building Science and Technology through the Building of Human Integrity. International Proceeding FORKOM-FKIP Indonesia, p. $13-14$

3. Elim HI (2017) Nanomedicine with Its Multitasking Applications: A View for Better Health. IJHMCR 2(2): 353-357.

4. Elim HI (2017)Physics of Multitasking Nanomedicine. IJHMCR 2(3): 509-519.

5. Elim HI, Mapanawang AL (2018) Al The Attractive Differences of Two
Types Of Herbal Medicine From Zingiberaceae Fruit (Golobe Halmahera). International Journal of Health Medicine and Current Research 3 (1): 799-806.

6. Mapanawang AL, Elim HI (2018) Chemical Bonding Character of Love Herbal Medicine. Journal of Nanomedicine and Nanotechnology 9: 63.

7. Elim HI, Mapanawang AL (2018) Electronics Physical System of Large Antioxidant Structure in Herbal Medicine based Zingiberaceae Fruit: Understanding and Application. Journal of Nanomedicine and Nanotechnology 9: 65.

8. Mapanawang AL, Elim HI (2018) Chemical Bonding Character of Love Herbal Medicine: A Prominent Medicine Candidate for Preventing HIV virus. Int J Nano Res Appl 1(1): 1-5.

9. Elim HI, Mapanawang AL (2018) Electronics Physical System of Large Antioxidant Structure in Herbal Medicine based Zingiberaceae Fruit: Understanding and Application. Int J Nano Res Appl 1(1): 1-4.

10. Mapanawang AL, Elim HI (2018) Unique Chemical Bonding Behavior of Love Herbal Medicine and Its Conjunction with Chemotherapy Drug. Journal of Nanomedicine and Nanotechnology p. 9

11. Alberts B (2011) Science Breakthroughs Science.

12. Popovic M, Sarngadharan MG, Read E, Gallo RC (1984) Detection, Isolation, and Continuous Production of Cytopathic Retroviruses (HTLVIII) from Patients with AIDS and Pre-AIDS. Science 224 (4648): 497-500.

13. Gallo RC, Salahuddin SZ, Popovic M, Shearer GM, Kaplan M, et al (1984). Frequent Detection and Isolation of Cytopathic Retroviruses (HTLV-III) from Patients with AIDS and at Risk for AIDS. Science 224(4648): 500503

14. Schüpbach J, Popovic M, Gilden RV, Gonda MA, Sarngadharan MG, et al. (1984) Serological Analysis of a Subgroup of Human T-Lymphotropic Retroviruses (HTLV-III) Associated with AIDS. Science 224(4648): 503505

15. Sarngadharan MG, Popovic M, Bruch L, Schüpbach J Gallo RC (1984) Antibodies Reactive with Human T-Lymphotropic Retroviruses (HTLVIII) in the Serum of Patients with AIDS. Science 224 (4648): 506-508.

16. Mapanawang AL, Sambode F, Killing M, Mapanawang S, Dijnimangake B, et al. (2016) Identification of Antioxidant Activity of Golobe Halmahera (Hornstedtiasp, Ingiberaceae) Fruit Extract. International Journal of Pharmacy Review \& Research 6(1): 31-34.

17. HI Elim, AL Mapanawang (2018) In Preparation.
Creative Commons Attribution 4.0 International License

For possible submissions Click Here

\section{Submit Article}

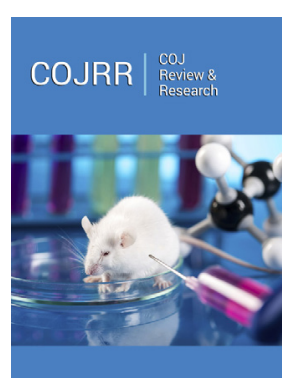

COJ Reviews \& Research

Benefits of Publishing with us

- High-level peer review and editorial services

- Freely accessible online immediately upon publication

- Authors retain the copyright to their work

- Licensing it under a Creative Commons license

- Visibility through different online platforms 